\title{
Telework Considerations for Public Managers with Strategies for Increasing Utilization
}

\author{
Frederick C. Day ${ }^{1}$ and Mark E. Burbach ${ }^{2}$ \\ ${ }^{1}$ Department of Agricultural Leadership, Education and Communications, University of Nebraska- \\ Lincoln, Nebraska, U.S.A \\ ${ }^{2}$ School of Natural Resources, University of Nebraska-Lincoln, Nebraska, U.S.A
}

\begin{abstract}
Literature was reviewed to investigate the extent of teleworking in public organizations and to identify management strategies to encourage telework utilization. The benefits of teleworking are contrasted with its challenges. Concepts grounded in Expectancy Theory, Leonard, Beauvais and Scholl's (1999) Meta-theory of Work Motivation, and to a lesser extent McClelland's Needs Trichotomy (Mc Clelland, 1966) are integrated to provide support for high performance telework management strategies. These strategies include developing an inventory of diverse team skills and competencies, promoting cognitive diversity, utilizing a collaborative management style, promoting trust and unity, facilitating the use of collaborative technology, introducing interdependence to tasks, and implementing a fair reward system. Finally, conclusions with implications for management and suggestions for future research are offered.
\end{abstract}

Keywords: Teleworking, Telecommuting, Virtual Teams, Management Strategies

\section{Introduction}

The U.S. Office of Personnel Management (OPM) (2006) defines telework as "work arrangements in which an employee regularly performs officially assigned duties at home or at other work sites geographically convenient to the residence of the employee" (p. 2). This includes fulltime or part-time work. Teleworking, often referred to as telecommuting, utilizes communications technology as a means of substitution for work-related travel and enables team members to interact virtually with one another without having to be physically present at the office at the same time. Similarly, Martins, Gilson, and Maynard (2004) define virtual teams as dispersed groups of people who "use technology to interact with one another across geographic, organizational, and other boundaries" (p. 805). Teleworking requires the use of communication technology and development of skills needed to interact virtually with team members but does not necessarily imply the existence of a virtual team. Virtual teams, in the purest sense, are teams made up of members based in different locations, possibly far from one another, across time zones and geographical boundaries. For purposes of this discussion, any references to virtual teams will imply geographical dispersion such that; it is not practical for all members to physically meet on a regular, frequent basis.

Virtual teams and teleworkers may each rely to a different extent upon synchronous communication (e.g., teleconferencing, videoconferencing, and instant messaging) and asynchronous communication (e.g., e-

Copyright (C) 2011 Frederick C. Day and Mark E. Burbach. This is an open access article distributed under the Creative Commons Attribution License unported 3.0, which permits unrestricted use, distribution, and reproduction in any medium, provided that original work is properly cited. Contact author: Frederick C. Day e-mail: fday@huskers.unl.edu 
mail and Internet-enabled collaboration tools) for team interactions. Virtual teams geographically dispersed across time zones often favor asynchronous communication methods because team members do not need to be available at the same time to collaborate. The degree of team member dispersion, therefore, drives the use of communication technology in virtual teams. Teleworking arrangements often entail team members based from the same office, working remotely from the field, home, or alternate locations such as temporary office facilities. Teleworkers may or may not physically meet with other team members on a regular, frequent basis.

The driver behind a decision to telework may be the nature of the work (e.g., work that must be performed in the field, provided onsite to support clients, or does not require physical interaction with other team members), perceived convenience afforded to the teleworker or other team members, frequent travel demands, anticipated cost savings from not having to maintain a physical office, or unplanned circumstances such as travel delays, illnesses, emergencies, and so forth. Also, the number of team members who telework may vary from one or a few employees to the entire team, as dispersion of members may not be a telework decision driver. The distinction in characterizing a work arrangement as telework versus virtual teamwork lies in the degree of team dispersion, the drivers behind the decision to work virtually, and the extent to which team interactions depend on communication technology. However, as teleworking is encouraged and more team members elect to telework, the closer the teleworking model becomes to virtual team leadership. Whether a supervisor or manager leads occasional teleworkers or geographically dispersed virtual teams, it's necessary to develop similar leadership, communication, and technical skills. Many of the benefits and challenges to teleworking are similar to those associated with virtual team leadership.

A number of authors have identified potential benefits and challenges of telework arrangements in private sector organizations from the perspectives of the employee, employer, environment, and society (e.g., Mello, 2007; Crandall and Gao, 2005). While distinctions between management in the private and public sectors can be debated (Rainey, 2009), the application of telework arrangements in public organizations, as well as, the preponderance of studies from the private sector calls for more perspective from public organizations. Indeed, some contend that firms with flatter management hierarchies and more flexible and less bureaucratic forms of work organization are more likely to foster telework (Clear and Dickson, 2005; Dimitrova, 2003); however, others contend that sector is not a critical factor shaping acceptance of telework (Taskin and Edwards, 2007). Research examining the outcomes of telework in public and private organizations has identified differences between the two (e.g., Cooper and Kurland, 2002; Staples, 1997). Moreover, the reasons to engage in telework may be different (Adobe Systems, Inc., 2009).

\section{Methods}

This study consists of a systematic review of empirical and conceptual articles published in scholarly journals, proceedings from scholarly conferences, and government websites on the topics of teleworking and virtual team management. The criteria used to select and assess the potential of articles included the following:

1. The article had to deal with some aspect of telecommuting, telework, teleworking, virtual teams, virtual leadership, eleadership, computer-mediated communication, flexible working, or motivation of virtual teams.

2. Peer-reviewed journal articles dealing with motivation of teams between 1980 and 2010 were included. Selected other articles published prior to this period were also included.

3. Remaining articles were published between 1990 and 2010, including peerreviewed journals, conference proceedings, books, magazines, online publications, etc. 
4. Articles retrieved were then categorized by theme and organizational sector (public or private) based upon a review of titles and abstracts to identify gaps in the literature.
From a categorization of articles retrieved, it became apparent that little research had been published on utilization of telework or virtual teams in the public sector. From 1,011 potentially relevant articles selected, 72 were included (Fig. 1) in this review.

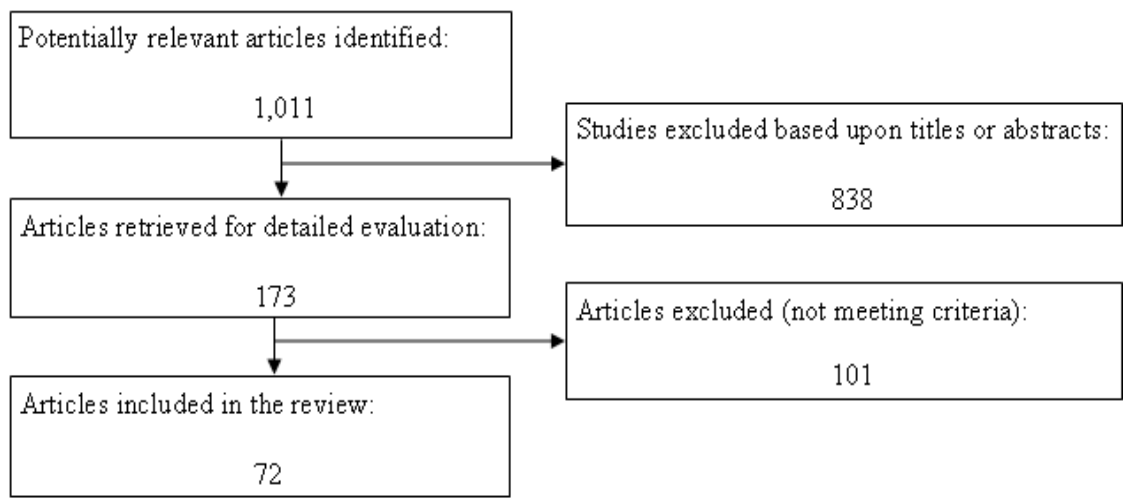

Fig. 1. Systematic Review Flow Diagram.

\section{Teleworking Utilization in Public Organizations}

The U.S. Chamber of Commerce reported in 2006, that 20 million people telework in the United States, with most telework arrangements in the private sector (Douglas, 2008). Of these 20 million people, it is estimated that approximately 15 million Americans worked from home during 2006. For the federal government, the U.S. Office of Personnel Management (2009) reported to the U.S. Congress that for 2008:

- only 102,900 out of $1,962,975$ (5.24\%) federal employees, representing 78 agencies, telework at least part-time; this represents an $8.72 \%$ increase in teleworking from the previous year.

- only $8.67 \%$ of the $1,187,244$ eligible federal employees telework.

- $78 \%$ of agencies inform employees of their eligibility to telework.

- $23 \%$ of agencies use electronic tracking of teleworkers.

- 27 of 78 agencies reported cost savings as a result of telework; most of these agencies also reported improved morale and increased productivity and employee retention as benefits.

- only about $56 \%$ of federal agencies integrate telework into their continuity of operations planning.

- office coverage, management resistance, organizational culture, information technology (IT) security, and IT funding were cited as barriers to implementing teleworking in the federal government.

All federal agencies are required to designate a telework coordinator to oversee telework programs and to offer telework opportunities to eligible federal employees. Bednarz (2007) reported that $65 \%$ of federal managers surveyed were unaware of telework opportunities offered by their agencies. However, recently the U.S. Office of Personnel Management (2009) and U.S. General Services Administration (2009) have made teleworking in federal government a high priority, promoting benefits to employees such as greater flexibility, personal savings on fuel consumption and other work expenses, and greater access to job openings. U.S. Office of Personnel Management director John Berry 
announced a plan in April 2009 to increase telework participation at the federal government level by directing agencies to establish telework policies, encouraging them to create a Telework Managing Officer position and implement an appeals process for employees who have been denied requests to telework, and providing telework training to both federal government managers and employees (Williams, 2009).

The percentages of teleworkers at the state and local government levels are similar to those at the federal level and also lag considerably behind the private sector (Ruth and Choudhury, 2008). Possible explanations for this difference in use abound but plausible reasons include the lack of management oversight and evaluation of telework programs in the public sector (Mihm, 2004; Steinhardt, 2007).

At the state government level, a few states have made teleworking a high priority (Opsahl, 2008). Virginia, for example, requires its state agencies to implement a telework policy, with $20 \%$ of eligible state government employees required to telework at least one day per week by 2010. Virginia has also integrated teleworking into its continuity of operations plans. Other states with telework initiatives include Arizona, California, Connecticut, Minnesota, Oregon, Texas, and Utah (Opsahl, 2008; Rhode Island Department of Administration [RIDA], 2002; Williams, 2009). Major cities that have telework initiatives include Dallas-Fort Worth, Phoenix, and San Diego (RIDA, 2002).

\section{Benefits of Teleworking}

Benefits of teleworking have been cited by numerous sources in American jurisdictions, as well as by researchers in other countries (Lee-Kelley and Sankey, 2008; Horowitz, Bravington and Silvis, 2006; Nedelko and Potočan, 2007). However, little attention has been paid to researching teleworking and virtual teams in the public sector. For example, LeeKelley and Sankey (2008) of the University of Surrey in the United Kingdom presented a qualitative case study contrasting levels of virtual team project success of two private sector data centers within an organization with operations in the AsiaPacific region to illustrate both challenges and beneficial ways in which global virtual teams create value. Likewise, Horowitz, Bravington and Silvis (2006) of the University of Cape Town in South Africa reported the results of a mixed-methods study including virtual team respondents in the private sector from 16 countries focusing on key factors in effectiveness and failure of virtual teams, and concluded that cross-cultural communication, managerial and leadership communication, supporting communication technology, goal and role clarification, and relationship building are most important to virtual team performance. Nedelko and Potočan (2007) of the University of Maribor in Slovenia presented a framework around which virtual teams are built and suggested that virtual teams are a solution for connecting globally dispersed members. The following benefits have been attributed to the use of teleworking arrangements in public organizations: greater flexibility, cost savings and employee retention, expanded work opportunities, improved productivity, higher employee satisfaction, fewer work delays or disruptions, and environmental friendliness.

\section{Greater Flexibility}

The flexible work environment offered by teleworking has become an attractive recruiting option for state and local government agencies. For example, in Texas, Virginia, Arizona and other jurisdictions, telework possibilities are featured as state agencies seek younger workers as Baby Boomers start to retire (Douglas, 2008; Opsahl, 2008). Teleworkers are able to work at home, in a satellite office, or in a temporary office location using a computer and a telephone. With greater work schedule flexibility, teleworkers are able to schedule personal time for doctor visits, financial planning, parent-teacher days, and other important events without having to schedule leave. Also, more opportunities to spend time with family and friends or to participate in community events are available (Mokhtarian and Salomon, 1997; "Benefits for employees," n.d.). The U.S. Merit 
Systems Protection Board (2003) reported that telework is one of the most desired family-friendly programs associated with government work. Workplace flexibility is second only to benefits packages on the list of what attracts new workers to state government employment (National Association of State Chief Information Officers [NASCIO], 2007). In a survey of employees of the City of San Diego, Mokhtarian and Salomon (1997) found that individuals who assign a high value to social or professional interaction at work are less likely to prefer telework. Also, telecommuters are more likely to be women, married, and have children (Wells, Douma, Loimer, Olson, and Pansing, 2001).

\section{Cost Savings and Employee Retention}

Organizations that offer telework alternatives achieve real estate cost reductions because less physical office space is needed ("Benefits for employees," n.d.). Also, expenses related to transportation, parking, food, and wardrobe may be reduced as teleworkers are able to work from home or alternate work sites (U.S. General Accounting Office, 2003). Salary and relocation costs of staff may be saved provided work can be performed remotely. Telework can also reduce environmental impacts and traffic in urban areas (Arnold, 2006).

The flexibility offered by teleworking should in theory attract employees, lead to higher employee retention, and reduce employee turnover. The U.S. Merit Systems Protection Board (2003) reported that of all the work-life programs it asked about in its 2000 Merit Principles Survey, only telework appeared to have a relationship between employees' intentions to leave their employment in the coming year and the lack of available telework options. Also, teleworkers are often able to retain their positions despite family moves necessary because another family member is changing jobs. Therefore, costs associated with recruitment, hiring, training, and staff turnover are reduced.

\section{Expanded Work Opportunities}

Work opportunities are not confined to jobs within commuting distance (Douglas, 2008). Teleworking can enable people in an area of high unemployment to have access to work opportunities in other areas. Skilled younger workers who are adept at collaborative technologies may seek opportunities in which they can utilize those skills (Douglas, 2008; U.S. General Services Administration and Telework Exchange, 2009). Work opportunities may also be provided for people with special needs or disabilities (e.g., for people with disabilities that make traveling to work difficult). Telework provides a reasonable accommodation to employees and job applicants with disabilities, as mandated by the Americans with Disabilities Act (U.S. Equal Employment Opportunity Commission, 2005). In addition to expanding the government labor pool by including more disabled and mobility restricted people, retired individuals, older workers, and part-time employees, telework relieves governments of geographical restrictions when recruiting for positions (Riccucci, 2002). Teleworking may be an attractive option for "highknowledge" employees who are nearing retirement but are willing to continue working from home ("Benefits for employees," n.d.). As previously noted, state and local government agencies in Texas, Virginia, Arizona, and other locations use telework capabilities to help in recruiting younger employees and retaining existing employees.

\section{Improved Productivity}

While it is sometimes thought that teleworkers will waste time absent direct supervision, government employees frequently report increased productivity from teleworking (Opsahl, 2008). While estimates do vary, studies have found that the average productivity gains of employees who engage in telework are $10 \%$ to $40 \%$ greater than the productivity they experience in an office environment (Mello, 2007). For example, the Fort Worth Department of Environmental Management reported a $90 \%$ productivity increase from employees who were selected for a sixmonth pilot program in 2007 allowing employees to telework part-time (Opsahl, 2008). Other state and municipal agencies (e.g., the University of Texas at Austin) that have implemented remote collaborative communications infrastructures have 
reported similar productivity gains from teleworking (Opsahl, 2008). Teleworkers experience fewer distractions and sick days and perform with higher efficiency than traditional employees. Because less time is wasted commuting to and from work, telework employees can concentrate on the work at hand and produce more in less time. Also, there is no need to miss work on snow days as long as electrical power remains available. Finally, teleworkers are often more self-reliant and skilled in the use of remote technologies ("Benefits for employees," n.d.).

Telework and flexible workplace policies can improve the morale and motivation of employees (U.S. Government Accountability Office, 1997). Personnel evaluations in the public sector have shown improved employee morale/quality of worklife issues associated with telework (Joice, 2000). Government teleworkers report improved job performance because telework assists them in dependent care responsibilities (Major, Verive, and Joice, 2008). Mongioi, McNally, and Thompson (2010) believe telework arrangements improve emergency preparedness because they allow continuity of operations. Telework arrangements also involve a display of trust and confidence in employees.

\section{Higher Employee Satisfaction}

Teleworkers frequently report higher levels of job satisfaction than do their coworkers who do not telework ("Benefits for employees," n.d.). Employees appreciate the trust and confidence shown to them by the organization's offering of a teleworking option, and they are often free to manage their own time to achieve a greater balance between work and family demands. Also, teleworkers who work from home save on personal expenses such as business attire, lunches, dry cleaning, and transportation. Because teleworkers spend more time working and less time commuting, they often have more time for friends, family, and community activities. Satisfaction with work/family balance is associated with job satisfaction in federal employees (Ezra and Deckman, 1996), and telework offers a means to meet the dual demands of family and work.
Cooper and Kurland (2002) compared teleworkers in public and private organizations and their sense of professional isolation caused by fewer opportunities for interpersonal networking, informal learning, and mentoring. They concluded that teleworkers in the public sector appeared to value informal developmental activities less than private employees, and thus, teleworking is less likely to hinder the professional development of public sector employees than that of employees in the private sector.

\section{Fewer Work Delays or Disruptions}

Teleworkers who work from home may avoid delays associated with traffic, weather conditions, and emergencies. For this reason, telework may be a key business continuity plan component in the event of a pandemic or any other crisis. The Telework Exchange, a public-private partnership that promotes government telework, recommended that all federal organizations implement telework programs to slow the spread of $\mathrm{H} 1 \mathrm{~N} 1 \mathrm{flu}$ (Williams, 2009). In response to the H1N1 threat, U.S. Office of Personnel Management director John Berry announced a plan to enhance federal telework policies by including elements of two bills that have been introduced to Congress: the Telework Improvement Act of 2009 and the Telework Enhancement Act of 2009. Under this plan, federal agencies would be directed to write policies that would ensure broad-based telework training for managers and employees. The NASCIO has recommended that all state governments include teleworking and cross-training of staff in pandemic plans to ensure uninterrupted delivery of services. A few states, including California and Virginia, have developed plans to utilize teleworking to ensure uninterrupted services in response to the H1N1 threat (Williams, 2009).

\section{Environmental Friendliness}

The U.S. Office of Personnel Management (2009) cited benefits of teleworking as establishing "green" workplaces, reducing employee fuel consumption, and containing pandemic influenza threats. The U.S. 
Bureau of Transportation Services (2006) projects that telework in the United States could lead to a reduction of up to 35 billion vehicle miles (56 billion kilometers) traveled per year with a resultant decline in gasoline consumption of up to 1.7 billion gallons (6.4 billion liters) of fuel. Telework can also alleviate the strain being placed on many public transportation systems (Harpaz, 2002). In addition, municipal governments, like the City of Austin, Texas, and the Fort Worth Department of Environmental Management have followed the federal government's recommendations for developing formal procedures to allow managers to authorize teleworking on bad air quality days (Opsahl, 2008). Teleworking reduces the number of commuters on highways, thus reducing pollution and fuel consumption. Also, because there is less need for road maintenance, communities can place greater emphasis on improving the quality of life for residents.

\section{Challenges of Teleworking}

Before initiating a teleworking arrangement, both management and employees need to be aware of certain inherent challenges.

\section{Assessing Competencies}

Matching teleworker skills with telework assignments is important to government telework program success (Naquin, 2009). In assessing virtual team member competencies, for example, managers should be sure that members possess complementary skills that overlap in addition to appropriate education and experience (Harvey, Novicevic, and Garrison, 2004). Team members should possess expertise in more than one area to overcome dependencies on individual team members who may be unavailable. Training opportunities should be provided to teleworkers to maximize performance and job satisfaction. Also, it is important for managers to identify skills and competencies suitable for telework and to develop these competencies among potential teleworkers. Fisher and Fisher (2001) suggest that employees who work virtually should be self-starters, possessing strong self-discipline and the ability to direct their own activities to complete tasks. Employees should talk with others who telework to gain an understanding of the level of discipline required and the level of interaction or support they can expect from a teleworking arrangement. In addition, teleworkers should be technically competent, able to exercise good judgment in making critical decisions, in possession of good interpersonal skills, and willing to take responsibility for work outcomes. In addition, supervisors should possess intercultural sensitivity, good listening skills, good verbal and written communication skills, and good facilitation and conflict-management skills.

\section{Developing Interpersonal Skills}

Some municipalities have reported that teleworking is effective when the jobs do not require much interaction with coworkers or the public and concrete, results-oriented goals are established (Opsahl, 2008). If public interaction or collaboration with co-workers is required, however, new employees may require some time to acquire and assimilate information about their organization and to establish work relationships. This is especially true for younger employees who may benefit from face-to-face interactions while developing social skills and a professional network before working in a teleworking arrangement. Without sufficient time in a conventional team setting to develop a network before teleworking, new employees may be at a disadvantage (Fisher and Fisher, 2001).

To capitalize on teleworkers' ideas and know-how, managers must develop interpersonal connections between teleworkers and others in the organization. Developing interpersonal networks for knowledge sharing and other necessary communications is a major challenge for public sector managers (Getha-Taylor and Lee, 2008).

\section{Maintaining a Productive Work Environment}

Teleworkers who work from home or from a temporary office location may not be well equipped in terms of technical communication infrastructure or an environment free of distractions for 
interaction and collaboration with other team members. The organization's financial support to ensure that teleworkers have appropriate equipment and communication capabilities might be lacking. For example, productivity was found to suffer in the Department of Information Systems in the City of Austin, Texas, because of a lack of supported remote collaborative communications infrastructure for telework (Opsahl, 2008). Lack of adequate equipment may affect productivity (Robertson, 2001). To overcome technical infrastructure issues, the State of Virginia established the Office of Telework Promotion and Broadband Assistance to encourage teleworking in both the public and private sectors and to provide broadband service throughout the state (Douglas, 2008). Likewise, the Telework Consortium, which is funded by grants from the U.S. Department of Commerce, and the Arizona Government Information Technology Agency have piloted programs to provide state and local agencies with teleconferencing, videoconferencing, web-conferencing, and other remote collaborative technologies (Douglas, 2008).

Individuals who are not accustomed to teleworking may miss personal face-to-face interactions and find that their productivity declines. Also, in the case of teleworkers who work from home, personal family commitments may interfere with work. For this reason, the Fort Worth Department of Environmental Management forbids teleworkers to simultaneously care for children or dependent adults (Opsahl, 2008). Fisher and Fisher (2001) note that "the success or failure of a work-at-home arrangement depends on the teleworker's personality, company support, family, peers, and customers, the availability of necessary technology, and the physical setup of the home office" (p. 106 ). Finally, managers must ensure that work objectives and performance measures are clear (Naquin, 2009).

With teleworking employees, managers are challenged to measure performance by results and not to be unduly influenced by physical absence (McDonald, Bradley, and Brown, 2008; Naquin, 2009; Rosenberg, 2008). When monitored remotely, performance tends to become more formalized (Cooper, Kurland, and Bailey, 1999). Managers and teleworkers must recognize and account for this reality. Finally, timely feedback and frequent communication between teleworkers and supervisors is imperative (Naquin, 2009). A chronic lack of knowledge sharing among teleworkers can adversely affect productivity (Breu and Hemingway, 2004).

\section{Organizational Culture Mismatch}

Command and control organization cultures are not conducive to collaborative management or developing a flexible work environment (Paul, Samarah, Seetharaman, and Mykytyn, 2004). Supervisors who have not been exposed to virtual management or had teleworking experiences may lack confidence in their ability to manage or supervise teleworkers. To compensate for the lack of direct oversight of work performed by teleworkers, supervisors may over-control teleworker activities through policies and procedures (e.g., requiring submission of detailed weekly activity reports). Instead of ensuring that teleworkers stay productive, a form of virtual micromanagement is practiced which results in diminished teleworker morale, trust, and productivity. Fisher and Fisher (2001) note that teleworkers who feel distrusted or over-controlled may; (a) become dependent on their supervisor, (b) look for ways to circumvent or resist compliance with controls, or (c) become apathetic. None of these behaviors is a desired work outcome.

\section{Difficulties in Sustaining Team Unity}

Teleworking can present difficulties in coordinating work within teams (Hertel, Geister, and Konradt, 2005). Supervisors and traditional team members may lose sight of contributions of teleworkers, or may inadvertently forget to include teleworkers on important meeting invitations. Teleworkers who are treated unequally may feel isolated, unappreciated, or as if they are not part of the team. Team collaboration may also suffer if either communications infrastructure or team facilitation skills are lacking. If team conflicts arise, resolution may require a face-to-face team meeting with all members present. 


\section{Difficulties in Protecting Public Information Security and Privacy}

A 2008 survey by Ernst \& Young LLP of 73 corporate and government organizations in the United States, Canada, and Europe revealed that only about half of the respondents had formal policies and training programs to protect the security and privacy of public information accessed by employees under home telework arrangements ("Report: Telecommuting," 2008). Indeed, a critical issue that needs to be addressed in any telework program is access to information, particularly information contained on computers or data storage devices that will be taken from the office and/or files that will be accessed from home, as well as maintaining the security of that information (Crandall and Gao, 2005). Indeed, Robertson (2001) found one of the biggest concerns public managers have with telework is "the ability to protect proprietary and sensitive data and monitor employee access to such data without invading individual privacy rights" (p. 3). In implementing a collaborative communication infrastructure to support teleworking, controls are needed to ensure that:

- confidential public information is not saved to portable media such as laptop computers, personal digital assistants (PDAs), CDs, and so forth.

- encryption technology is used to protect computer hard drives or PDAs used by teleworkers.

- Wireless Internet connections are secured (e.g., using Microsoft's WPA or WPA2 encryption).

- policies concerning user access, downloading of non-approved software, the use of peer-to-peer file-sharing applications, external e-mail programs, and instant messaging are enforced.

- employee background checks are periodically made and reviewed for individuals who access public information.

In addition, it is important for government agencies to be able to monitor compliance with security and privacy policies of both traditional employees and teleworkers in order to safeguard the privacy of public information.

\section{Motivation and Telework Performance}

To maximize the benefits of telework, managers need to understand how motivation affects telework performance. The following discussion attempts to integrate concepts grounded in Expectancy Theory, Leonard, Beauvais and Scholl's (1999) Meta-theory of Work Motivation and to a lesser extent McClelland's Needs Trichotomy (Mc Clelland, 1966) to provide support for high performance telework management strategies.

\section{Implications of Expectancy Theory}

Expectancy theory explains decisions as a rational choice among alternatives, whereby the motivational force (MF) of each alternative is computed as the product of three factors: expectancy, instrumentality, and valence, where expectancy is the probability that an individual is capable of performing tasks required by the alternative, instrumentality is the likelihood that performance will lead to a positive outcome, and valence is the strength of one's preference for achieving a positive outcome (Ilgen, Nebeker, and Pritchard, 1981).

Self-efficacy, as a measure of "expectancy", was defined by Geister, Konradt and Hertel (2006) as the "perceived capability" (p. $461)$ to complete tasks. Geister, Konradt and Hertel (2006) cited field experiments with telecommuters by Higgins, Hulland, and Staples (1999) which demonstrated that "perceived self-efficacy correlated with performance, work satisfaction and stress management" (p. 461). In addition, Hertel, Geister and Konradt (2005) suggest that performance feedback should be frequent, concrete, and timely to increase virtual team member self-efficacy and expectancy. Several studies have found that participation in goal-setting, planning, and decision-making, as well as feedback on task fulfillment have a positive impact on team member motivation (Hertel, Konradt, and Orlikowski, (2004); Geister, Konradt, and Hertel (2006); Locke and Latham, 1990). Research based upon the Collective 
Effort Model and game theory as cited by Geister, Konradt and Hertel (2006) illustrates the direct impact of positive feedback on member self-efficacy and expectancy.

Geister, Konradt and Hertel (2006) noted that interpersonal trust has a positive influence on valence, a measure of the strength of one's identification with team goals, and is an important precursor to successful virtual team performance. Conversely, research by Lipnack and Stamps (1997) as cited by Geister, Konradt and Hertel (2006) found that deficient communication of virtual team goals had the effect of reducing member "valence" or identification with team goals. Valence increases with specificity and difficulty of goals, member participation in setting goals, and sense of trust and community (Geister, Konradt, and Hertel, 2006).

Instrumentality was found by Geister, Konradt and Hertel (2006) to increase among virtual team members in response to the team leader's use of empowerment, clear framing of task assignments and transparent communications of team member contributions in completing tasks. In addition, instrumentality was found to increase with the team members' perception that their contributions are indispensible (Geister, Konradt, and Hertel, 2006). Harvey, Novicevic and Garrison (2004) also found a positive relationship between cognitive diversity of teams and instrumentality.

The manager may seek to increase instrumentality and motivation by leveraging multiple intelligences and cognitive diversity within the telework team, such that individual team members may consult with other team members. Possessing desired skills, competencies and intelligences, however, does not guarantee success in working in a telework environment if team members lack the motivation to work in a virtual environment. Each individual team member possesses intelligence to varying degrees in solving problems and accomplishing team objectives. Harvey, Novicevic and Garrison (2004) suggest that virtual teams should represent a variety of intelligences, categorized as analytical, practical or creative. Analytical intelligence includes planning, implementation, and evaluation skills needed in solving problems and in acquiring knowledge (Harvey, Novicevic, and Garrison, 2004). Practical intelligence refers to one's use of common sense and intuition in adapting to environmental changes (Harvey, Novicevic, and Garrison, 2004). Creative intelligence refers to one's innovativeness in solving problems (Harvey, Novicevic, and Garrison, 2004). Ideally, the individual differences in intelligence will enhance the quality of decisions and improve the outcomes of team performance (Harvey, Novicevic, and Garrison, 2004). On the basis of Expectancy Theory, developing multiple intelligences should increase instrumentality and motivational force as the likelihood of improved outcomes increases (Ilgen, Nebeker, and Pritchard, 1981).

In developing cognitive diversity, Harvey, Novicevic and Garrison (2004) suggest that virtual teams should employ a variety of cognitive styles, categorized as monarchial, hierarchical, oligarchial, or anarchical. A monarchial cognitive style is characterized by high goal commitment and achievement orientation. A hierarchical cognitive style is characterized by prioritization of goals. An oligarchial cognitive style is characterized by one's ability to multitask. An anarchical cognitive style is characterized by one's use of creativity in solving problems. Presumably, assembling a combination of complementary cognitive styles among motivated team members should result in better quality decisions, improved team performance, and overall higher levels of satisfaction among team members (Harvey, Novicevic, and Garrison, 2004).

\section{Implications of the Meta-theory of Motivation}

Leonard, Beauvais, and Scholl (1999) identified five sources of work motivation:

(a) intrinsic process motivation,

(b) internal self concept,

(c) external self concept,

(d) instrumental motivation, and

(e) goal internalization. 
Intrinsic process motivation is motivation that results from the pleasure experienced from work activities, and can be distinguished from other sources of work motivation by the fun or pleasure that one receives doing the work (Leonard, Beauvais and Scholl, 1999). Internal self concept motivation is the internal drive to act or behave in ways that are consistent with one's traits, competencies, and values. Internal self concept motivation is distinguished from other motivation sources in the internal drive to prove one's competency. External self concept motivation arises from the external feedback one receives from others, helping to define one's self concept by reinforcing traits, competencies, and values. External self concept motivation is distinguished from other motivation sources by the tendency one has to display achievements and rewards to gain acceptance from others. Instrumental motivation arises from incentives or rewards that are offered in return for achieving desired results. The tangible nature of the reward that is offered distinguishes instrumental motivation from other sources of work motivation. Goal internalization is the motivation that arises from a need to pursue a cause that one believes in, consistent with one's values (Leonard, Beauvais and Scholl, 1999). A person who is high in goal internalization sometimes performs at a low level unless he or she is working for a cause that is important to that person.

Managers who are accountable for team performance should make it possible for teleworkers and virtual team members to satisfy their work related needs as described by Leonard, Beauvais, and Scholl's (1999) Meta-theory of Work Motivation. If virtual team members are motivated by intrinsic process, it is important for managers to assign tasks whenever possible that the teleworker enjoys. If the virtual team member is motivated by internal self-concept the manager should give assignments that the teleworker finds challenging and requires the teleworker's expertise; and the manager should emphasize the importance of the teleworker's skills toward the success of the operation. If the virtual team member is external self-concept the manager should offer frequent public praise and recognition and assign tasks that are "visible" to other team members. If the virtual team member is motivated by goal internalization the manager should frequently communicate the organization's mission and communicate how tasks being performed help to achieve the organization's mission. If the virtual team member is motivated by instrumental motivation, the manager should let teleworkers know what compensation or rewards they will get for their efforts and create incentives attached to predetermined objectives and tasks.

Also, Geister, Konradt and Hertel (2006) note the motivational importance of participation in planning, decision-making, and feedback on task completion. Participation in planning and decisionmaking leads to goal internalization and commitment to team goals (Geister, Konradt, and Hertel, 2006). Positive performance feedback increases member self-confidence and is an important source of external self concept motivation (Geister, Konradt, and Hertel, 2006). In addition, Kirkman, Rosen, Tesluk, and Gibson (2004) found a positive relationship between empowerment (a source of instrumental motivation) and virtual team performance, with the number of face-toface interactions beneficially moderating this relationship. In short, managers of teleworkers and virtual teams should be less controlling and more empowering, and they need to do more listening, coaching and facilitating than managers of traditional teams.

\section{Management Strategies to Encourage Telework Utilization}

According to Joice (2000), the main factors limiting growth of the federal telework initiative "are rooted in individual and organizational resistance to change, especially when it comes to ingrained attitudes and behaviors" (p. 6). In evaluating a pilot telework program for the Louisiana Department of Health and Hospitals, Naquin (2009) found seniorlevel buy-in was critical to the success of the program. The following are strategies, identified through a review of literature on virtual collaboration, to encourage 
utilization and minimize resistance to telework. These strategies would be applicable to public organizations wishing to encourage traditional employees to telework or to public organizations utilizing pure virtual teams.

\section{Develop an Inventory of Diverse Team Skills and Competencies}

Teleworkers and virtual teams, in general, may need to possess competencies in a number of functional areas, and members should complement one another in terms of education, skills, and cognitive diversity (Harvey, Novicevic, and Garrison, 2004). Therefore, it is important that training opportunities be provided to all team members. It is also important for the team leader to maintain an inventory of team member skills and competencies, and to develop additional competencies among team members (Harvey, Novicevic, and Garrison, 2004).

\section{Utilize a Collaborative Management Style}

A collaborative management approach in which teleworkers are empowered to manage their own activities is recommended. Rather than trying to control the activities of teleworkers, supervisors should coach, lead by influence rather than authority, mentor, and provide feedback on performance. Geister et al. (2005) suggest that performance feedback should be frequent, concrete, and timely. Also noted were studies by Huang and Lai (2001) and Weisband (2002) that suggest providing feedback to team members via computer-supported communications enhances team member motivation, satisfaction, and performance. However, Geister et al. suggest that the use of hardware-based electronic performance monitoring is ill-suited for virtual management, as the added stress, loss of trust, and resulting team member dissatisfaction would negate any performance gains.

\section{Promote Trust and Unity}

Geister et al. (2005) demonstrated that employees' getting acquainted face-to-face before working virtually facilitates development of cooperation and trust among team members. This may occur because meeting face-to-face allows team members to connect on a personal level. Performing competently, acting with integrity, and displaying concern for the well-being of others also promote trust (Duarte and Snyder, 2006). If possible, teleworkers should occasionally meet faceto-face with other team members to help develop team unity. Periodic team conference calls or videoconference calls should further improve the sense of unity and trust among team members.

\section{Facilitate the Use of Collaborative Technology}

Hertel, Deter, and Konradt (2003) found that computer-mediated teams performed at a higher level during group work than did individuals, as is the case with traditional face-to-face teams. Olaniran (1996) suggested that in order to encourage acceptance of group collaborative systems, systems should be easy to use, facilitate sharing of ideas and information, and allow reliable, adequate, and equal participation. Further, Hambley, O'Neill, and Klein (2007) found that team interactions and cohesiveness are influenced by the perceived accessibility and ease of collaboration and sharing of information via the selected communication medium. Another consideration in the selection of technology and communication medium is the use of project websites or web portals to foster a sense of community.

A strategy that the team leader may find beneficial is to make collaborative technology and communication media available to all team members in a laboratory or classroom setting and provide opportunities for team members to train to encourage technology use. A public organization operating under tight budgetary constraints may invest in technology without investing in training. Consequently, technology becomes underutilized or is not fully accepted by team members. By encouraging the use of collaborative technology, more team members will be encouraged to telework. Major, Verive, and Joice (2008) found that federal teleworkers believe that improved "hardware and software that supports 
telework would facilitate job performance and expand the types of tasks that can be done at home" (p. 81).

\section{Introduce Interdependence to Member Tasks}

Hertel, Konradt, and Orlikowski (2004) found that high task interdependence among assignments to team members who collaborate virtually, enhances trust and team effectiveness during the early stages of team development by building a sense of unity and individual contribution. One strategy to build team unity and encourage full team collaboration is to distribute interdependent tasks to team members.

\section{Implement a Fair Reward System}

Lawler (2003) suggests that implementing a fair reward system that is aligned with team goals and performance is important for motivating team members to work together cohesively. This suggestion is not unique to virtual teams or teleworkers but rather is applicable to any situation in which teamwork is critical. However, the reward system should also accommodate exceptional individual performance that has a positive impact on the achievement of team goals. A majority of surveyed federal teleworkers believe telework eligibility approval processes could be more fair and consistent (Major, Verive, and Joice, 2008).

\section{Conclusions and Suggestions for Future Research}

A number of benefits to teleworking have been recognized by federal, state, and local governments, but teleworking is underutilized by government managers. Government managers need both soft and hard technical skills to successfully lead employees from a distance. Managers who encourage employees to telework must rely upon communication technologies to connect with and influence team members who may be functionally, cognitively, and culturally diverse. Managers need to be socially astute, culturally aware, and able to articulate a vision that inspires, unites, and motivates team members to collaborate in order to achieve shared goals. To overcome barriers to teleworking, some government leaders have made the implementation of telework programs a priority and have established teleworking quotas and training programs for both managers and employees. Additional effort is still needed to institutionalize the use of remote collaborative communication technology to encourage government employees to telework.

Specific recommendations for managers to encourage and successfully utilize telework include:

- occasionally scheduling face-to-face meetings and scheduling periodic conference calls with both traditional employees and teleworkers to develop trust and team unity;

- making collaborative technology and communication media available to all team members in a laboratory or classroom setting, and providing telework training opportunities for all team members;

- distributing interdependent tasks to team members, to the extent possible, during the early stages of team development;

- implementing a fair reward system that is aligned with team goals and performance but that is flexible enough to reward for outstanding individual performance.

Areas in which further research is needed are teleworker and virtual leader development and assessment of the impact of gender on collaborative team interactions. Additional research is needed to answer the question of how an employee acquires the skills needed to telework effectively. In reviewing the literature, little research in this area was noted. Even if one possesses the requisite skills and competencies needed to be successful in a virtual environment, this does not mean the individual will have the discipline or motivation to work in such an environment (Fisher and Fisher, 2001).Additional research is needed to better understand the relationships between success or performance in a virtual work environment and individual characteristics such as personality and sources of motivation. Also, the relative lack of research assessing the impact of gender on collaborative team 
interactions was surprising because gender has been found to have an impact on online discussion interactions among distant learners (Kramarae, 2003). Nicholas and Guzzman (2009) found that male Millennials (Millennials being defined as those born between 1981 and 1999) indicated a higher preference for teleworking than did their female counterparts based on a positive perception of task autonomy. However, it is unknown whether the results of this study may be generalized to other age groups or in an actual work setting, as the sample was drawn from students at a private northeastern United States university. Additional research is needed in this area as well.

A number of studies have looked at predictors of teleworker success in the private sector (e.g., O'Neill, Hambley, Greidanus, MacDonnell, and Kline, 2009). The characteristics of telework success in the private sector are assumed to apply to the public sector (e.g., Telework Exchange, 2010). However, Bailey and Kurland (2002) warn researchers of errors in implicit and explicit assumptions about teleworkers and the practice of telework. Private sector studies of telework should be replicated in the public sector.

\section{References}

Adobe Systems, Inc. (2009). "Telework and Continuity of Operations: Different Goals, Common Technologies," [Retrieved June28, 2010],

http://www.teleworkexchange.com/resou rce-center-resources-tele-coop.asp

Arnold, J. T. (2006). "Making the leap: Train Supervisors to Overcome their Hesitance to Manage Teleworkers," HR Magazine, 51 (5), 80-86.

Bailey, D. E. \& Kurland, N. B. (2002). “A Review of Telework Research, Findings, New Directions, and Lessons for the Study of Modern Work," Journal of Organizational Behavior, 23 (4), 383-400.

Bednarz, A. (2007). "Federal Managers Clueless about Telework Support, Study Says," Network World. [Retrieved March 27 , 2010], http://www.networkworld.com/news/20

07/012207-federal-managers-

telework.html

Benefits for Employees. (n.d.), Retrieved from

http://www.teleworktoolkit.com/employe e_benefits.html

Breu, K. \& Hemingway, C. J. (2004). "Making Organisations Virtual: The Hidden Cost of Distributed Teams," Journal of Information Technology, 19 (3), 191-202.

Publisher - Google Scholar - British Library Direct

Clear, F. \& Dickson, K. (2005), "Teleworking Practice in Small and Medium-Sized Firms: Management Style and Worker Autonomy," New Technology, Work and Employment, 20 (3), 218-233.

Cooper, C. D. \& Kurland, N. B. (2002). "Telecommuting, Professional Isolation, and Employee Development in Public and Private Organizations," Journal of Organizational Behavior, 23 (4), 511-532. Publisher - Google Scholar - British Library Direct

Cooper, C., Kurland, N. \& Bailey, D. (1999, August). "Telecommuting: Manager Control and Employee Development in One Public and Two Private Organizations," Paper presented at the Academy of Management Annual Conference, Chicago, IL.

Crandall, W. \& Gao, L. (2005). "An Update on Telecommuting: Review and Prospects for Emerging Issues," S.A.M. Advanced Management Journal , 70 (3), 30-37.

Dimitrova, D. (2003). "Controlling Teleworkers: Supervision and Flexibility Revisited," New Technology, Work and Employment, 18 (3), 181-195.

Douglas, M. (2008, April 4). "Telework Helps Virginia and Arizona Recruit and Retain Employees," Government Technology Magazine.[Retrieved March 27, 2010],

Duarte, D. L. \& Snyder, N. T. (2006). Mastering Virtual Teams: Strategies, Tools, and Techniques That Succeed, Jossey-Bass, San Francisco, California. 
Ezra, M. \& Deckman, M. (1996). "Balancing Work And Family Responsibilities: Flextime And Child Care In Federal Government," Public Administration Review, 56 (2), 174-179.

Fisher, K. \& Fisher, M. D. (2001). The Distance Manager: A Hands-on Guide to Managing Off-site Employees and Virtual Teams, McGraw Hill, New York, New York.

Geister, S., Konradt, U. \& Hertel, G. (2006). "Effects of Process Feedback on Motivation, Satisfaction, and Performance in Virtual Teams," Small Group Research, 37 (5), 459489.

Getha-Taylor, H. \& Lee, J. (2008). “Changing Competencies for Human Resource Management: Examining E-Government Scorecard and Federal Human Capital Survey Evidence," International Journal of Public Sector Performance Management, 1 (2), 150-166.

Hambley, L. A., O'Neill, T. A. \& Klein, T. J. B. (2007). "Virtual Team Leadership: The Effects of Leadership Style and Communication Medium on Team Interaction Styles and Outcomes," Organization Behavior and Human Decision Processes, 103 (1), 1-20.

Harpaz, I. (2002). "Advantages and Disadvantages of Telecommuting for the Individual, Organization, and Society," Work Study, 51 (2), 74-80.

Harvey, M., Novicevic, M. M. \& Garrison, G. (2004). "Challenges to Staffing Global Virtual Teams," Human Resource Management Review, 14 (3), 275-294.

Hertel, G., Deter, C. \& Konradt, U. (2003). "Motivation Gains in Computer-Supported Groups," Journal of Applied Social Psychology, 33 (10), 2080-2105.

Hertel, G., Geister, S. \& Konradt, U. (2005). "Managing Virtual Teams: A Review of Current Empirical Research," Human Resource Management Review, 15 (1), 6995.

Hertel, G., Konradt, U. \& Orlikowski, B. (2004). "Managing Distance by
Interdependence: Goal Setting, Task Interdependence, and Team-Based Rewards in Virtual Teams," European Journal of Work and Organizational Psychology, 13 (1), 1-28.

Horowitz, F. M., Bravington, D. \& Silvis, U. (2006). "The Promise of Virtual Teams: Identifying Key Factors in Effectiveness and Failure," Journal of European Industrial Training, 30 (6). 472-494.

Huang, W. \& Lai, V. (2001). "Can GSS Groups Make Better Decisions and Feel Good at the Same Time? A Longitudinal Study of Asynchronous GSS Groups," Proceedings of the 34th Annual Hawaii International Conference on System Sciences, vol. 1, Washington, DC, IEEE. [Retrieved April1, 2010],

Ilgen, D. R., Nebeker, D. M. \& Pritchard, R. D. (1981). "Expectancy Theory Measures: An Empirical Comparison in an Experimental Simulation," Organizational Behavior and Human Performance, 28 (2), 189-223.

Joice, W. (2000). "'Federal Telework Topics,' Telework: The new workplace of the 21st century" (pp. 155-167), U.S. Department of Labor, Washington, DC.

Kirkman, B. L., Rosen, B., Tesluk, P. E., \& Gibson, C. B. (2004). "The Impact of Empowerment on Virtual Team Performance: The Moderating Role of FaceTo-Face Interaction," The Academy of Management Journal, 47 (2), 175-192.

Kramarae, C. (2003). "Gender Equity Online: When There Is No Door to Knock on," Handbook of Distance Education, Moore, M. G, and Anderson, W. G. (eds), (pp. 261-272), Lawrence Erlbaum Associates, Mahwah, New Jersey.

Lawler, E. E., III. (2003). "Pay Systems for Virtual Teams," Virtual Teams That Work: Creating Conditions for Effective Virtual Teams, Gibson, C. B. and Cohen, S. G. (eds), (pp. 121-144), Jossey-Bass, San Francisco, California.

Lee-Kelley, L. \& Sankey, T. (2008). “Global Virtual Teams for Value Creation and Project Success: A Case Study," International Journal of Project Management, 26 (1), 51-62. 
Leonard, N. H., Beauvais, L. L. \& Scholl, R. W. (1999). "Work Motivation: The Incorporation of Self-Concept-Based Processes," Human Relations, 52 (8), 969999.

Locke, E.A. \& Latham, G. P. (1990), “A Theory of Goal Setting \& Task Performance," Prentice Hall, Englewood Cliffs, New Jersey.

Major, D. A., Verive, J. M. \& Joice, W. (2008). "Telework as a Dependent Care Solution: Examining Current Practice to Improve Telework Management Strategies," The Psychologist-Manager Journal, 11 (1), 6591.

Martins, L. L., Gilson, L. L. \& Maynard, M. T. (2004). "Virtual Teams: What Do we Know and Where Do we Go From Here?," Journal of Management, 30 (6), 805-835.

McClelland, D. (1966). "That Urge to Achieve," Think Magazine, 32 (6), 19-23.

McDonald, P., Bradley, L. \& Brown, K. (2008). "Visibility in the Workplace: Still an Essential Ingredient for Career Success?," The International Journal of Human Resource Management, 19 (12), 21982215.

Mello, J. A. (2007). "Managing Telework Programs Effectively," Employee Responsibilities and Rights Journal, 19 (4), 247-261.

Mihm, C. (2004). "Human Capital: Key Practices to Increasing Federal Telework. Testimony before the Committee on Government Reform, House of Representatives," July 8, 2004, U.S. General Accounting Office, GAO-04-950T.

Mokhtarian, P. L. \& Salomon, I. (1997). "Modeling the Desire to Telecommute: The Importance of Attitudinal Factors in Behavioral Models," Transportation Research Part A: Policy and Practice., 31 (1), 35-50.

Mongioi, F. T., McNally, L. M. \& Thompson, R. E. (2010). "Ensuring Workforce Mobility in Emergencies," ICF International, Fairfax, Virginia.
Naquin, S. S. (2009). "An Evaluation of the DHH Telecommuting Pilot Program," Report to the Louisiana Department of Health and Hospitals. [Retrieved June 2, 2010],

http://www.dhh.louisiana.gov/offices/rep orts.asp?ID=92\&Detail $=635 \&$ Arch $=2009$

National Association of State Chief Information Officers. (2007). "State IT Workforce: Here Today, Gone Tomorrow?," NASCIO, Lexington, Kentucky.

Nedelko, Z. \& Potočan, V. (2007). "The Role of Information and Communication Technology in Virtual Organizations," Proceedings of the 2007 Information and Intelligent Systems (IIS) Conference, September 12-14, 2007, Varaždin, Croatia.

Nicholas, A. J. \& Guzzman, I. R. (2009). "Is Teleworking for the Millennials?," Proceedings of the 2009 ACM SIGMIS Computer Personnel Research Conference, May 28-30, 2009, Limerick, Ireland.

Olaniran, B. A. (1996). “A Model of Group Satisfaction in Computer-Mediated Communication and Face-To-Face Meetings," Behaviour and Information Technology, 15 (1), 24-36.

O'Neill, T. A., Hambley, L. A., Greidanus, N. S., MacDonnell, R. \& Kline, T. J. B. (2009). "Predicting Teleworker Success: An Exploration of Personality, Motivational, Situational, and Job Characteristics," New Technology, Work \& Employment, 24 (2), 144-162.

Opsahl, A. (2008, July 28). "Fort Worth and Other Munis Turn to Telework Amid BeltTightening," Government Technology Magazine. [Retrieved March 27, 2010],

Paul, S., Samarah, I., Seetharaman, P. \& Mykytyn, P. P. (2004). "Impact of Heterogeneity and Collaborative Conflict Management Style on the Performance of Synchronous Global Virtual Teams," Information and Management, 41 (3), 303321.

Rainey, H. G. (2009). "Understanding and Managing Public Organizations," (4th ed), Jossey-Bass, San Francisco, California. 
Report: Telecommuting Presents Privacy and Security Risks to Organizations. (2008, July 30). Government Technology Magazine.[Retrieved March 27, 2010], http://www.govtech.com/gt/381669?id=3 81669\&full=1\&story_pg=1

Rhode Island Department of Administration. (2002). "Teleworking Today: Trends in State-Level Implementation," Rhode Island Department of Administration Statewide Planning Program Technical Paper 151, Rhode Island Department of Administration, Providence, Rhode Island.

Riccucci, N. M. (2002). "Managing Diversity in Public Sector Workforces," Westview Press, Cambridge, Massachusetts.

Robertson, R. E. (2001). "Telecommuting: Overview of Challenges Facing Federal Agencies," (GAO-01-1116T), U.S. General Accounting Office, Washington, DC.

Rosenberg, A. (2008). "Time for Telework," Government Executive, 40 (10), 49-54.

Ruth, S., \& Choudhury, I. (2008). "Telework: A Productivity Paradox?," IEEE Internet Computing, 12 (6), 80-83.

Staples, D. S. (1997). "An Investigation of Information Technology-Enables Remote Management and Remote Work Issues," Australasian Journal of Information Systems, 4 (2), 82-91.

Steinhardt, B. (2007). "Human Capital: Greater Focus on Results in Telework Programs Needed," Testimony before the Subcommittee on Oversight of Government Management, the Federal Workforce, and the District of Columbia, Committee on Homeland Security and Governmental Affairs, U.S. Senate, June 12, 2007, (GAO07-1002T), U.S. Government Accountability Office, Washington, DC.

Taskin, L. \& Edwards, P. (2007). "The Possibilities and Limits of Telework in A Bureaucratic Environment: Lessons from the Public Sector," New Technology, Work and Employment, 22 (3), 195-207.

Telework Exchange. (2008). "How Much Is Too Much? America's Addiction to Gasoline and Its Impact on the Workforce,"
[Retrieved March 27, 2010], http://www.teleworkexchange.com/gasad diction/slides.asp?slide=1

Telework Exchange. (2010). "What is Telework Exchange?," [Retrieved June 8, 2010],

http://www.teleworkexchange.com/about. asp

U.S. Bureau of Transportation Services. (2006). "Transportation Implications of Telecommuting," National Transportation Library, A Program of the Bureau of Transportation Services. [Retrieved April 17, 2010], http://ntl.bts.gov/DOCS/telecommute.html

U.S. Equal Employment Opportunity Commission. (2005). "Work at Home/Telework as a Reasonable Accommodation," [Retrieved April 17, 2010], .

http://www.eeoc.gov/facts/telework.html

U.S. Government Accountability Office. (1997). "Federal Workforce: Agencies' Policies and Views on Flexiplace in the Federal Government," U.S. Government Accountability Office, Washington, DC.

U.S. General Accounting Office. (2003). "Human Capital: Further Guidance, Assistance, and Coordination Can Improve Federal Telework Efforts," (GAO-03-679), U.S. General Accounting Office, Washington, DC.

U.S. General Services Administration and Telework Exchange. (2009). "The Benefits of Telework," [Retrieved March 27, 2010], http://www.teleworkexchange.com/pdfs/ The-Benefits-of-Telework.pdf

U.S. Merit Systems Protection Board. (2003). "The Federal Workforce for the 21st Century: Results of the Merit Principles Survey 2000," U.S. Merit Systems Protection Board, Washington, DC.

U.S. Office of Personnel Management. (2006). "A Guide to Telework in the Federal Government," (OPM-II-A1). U.S. Office of Personnel Management, Washington, DC. 
U.S. Office of Personnel Management. (2009). "Status of Telework in the Federal Government: Report to the Congress," [Retrieved March 27, 2010],

http://www.docuticker.com/?p=27871

Weisband, S. (2002). "Maintaining Awareness in Distributed Team Collaboration: Implications for Leadership and Performance," Distributed Work, Hinds, P. and Kiesler, S. (eds), (pp. 311334). MIT Press, Cambridge, Massachusetts.

Wells, K., Douma, F., Loimer, H., Olson, L. \& Pansing, C. (2001)."Telecommuting Implications for Travel Behavior: Case Studies from Minnesota," Transportation Research Record, 1752, 148-56.

Williams, M. (2009, April 30). "Swine flu: Agencies Scramble to Update Telecommuting Policies" Government Technology Magazine,[Retrieved June 8, 2010]

http://www.govtech.com/gt/652450 